\title{
Contrasting effects of iron reduction on thionation of diphenylarsinic acid in a biostimulated Acrisol
}

\author{
Meng Zhu ${ }^{1,2,3} \cdot$ Yongming Luo ${ }^{2,3,4} \cdot$ Nannan Cheng ${ }^{1} \cdot$ Ruyi Yang ${ }^{1,3} \cdot$ Juqin Zhang ${ }^{1} \cdot$ Mengyun Zhang $^{1} \cdot$ Peter Christie $^{4}$
}

Received: 8 July 2019 / Accepted: 14 February 2020 / Published online: 4 March 2020

(C) Springer-Verlag GmbH Germany, part of Springer Nature 2020

\begin{abstract}
Diphenylarsinic acid (DPAA) is an emerging phenylarsenic compound derived from chemical warfare agents. It has been suggested that biostimulation of sulfate reduction decreases the concentrations of DPAA in soils. However, biostimulation often induces $\mathrm{Fe}$ (III) reduction which may affect the mobility and thereby the transformation of DPAA. Here, a soil incubation experiment was carried out to elucidate the impact of Fe(III) reduction on the mobilization and transformation of DPAA in a biostimulated Acrisol with the addition of sulfate and lactate. DPAA was significantly mobilized and then thionated in the sulfide soil (amended with sulfate and sodium lactate) compared with the anoxic soil (without addition of sulfate or sodium lactate). At the start of the incubation period, $41.8 \%$ of the total DPAA in sulfide soil was mobilized, likely by the addition of sodium lactate, and DPAA was then almost completely released into the solution after 2 weeks of incubation, likely due to Fe(III) reduction. The relatively low fraction of oxalate-extractable Fe in Acrisol, which contributes significantly to DPAA sorption and is more active and reduction-susceptible, may explain the observation that only $<40 \%$ of the Fe(III) (hydr)oxides were reduced when DPAA was completely released into the solution. A more rapid and final enhanced elimination of DPAA was observed in sulfide soil and the fraction of total DPAA decreased to 60.1 and $91.0 \%$, respectively, at the end of the incubation in sulfide soil and anoxic soil. The difference appears to result from increased DPAA mobilization and sulfate reduction in sulfide soil. On the other hand, the formation of FeS precipitate, a product of $\mathrm{Fe}$ and sulfate reduction, may reduce the efficiency of DPAA thionation. Accordingly, the potentially contrasting effects of Fe(III) reduction on DPAA thionation need be considered when planning biostimulated sulfate reduction strategies for DPAA-contaminated soils.
\end{abstract}

Keywords Diphenylarsinic acid $\cdot$ Iron reduction $\cdot$ Thionation $\cdot$ Biostimulation $\cdot$ Sulfate reduction $\cdot$ Acrisol

\section{Introduction}

Chemical warfare agents containing Clarks I (diphenylchloroarsine) and II (diphenylcyanoarsine) were widely produced and used during the world wars in the

\section{Responsible editor: Diane Purchase}

Electronic supplementary material The online version of this article (https://doi.org/10.1007/s11356-020-08107-6) contains supplementary material, which is available to authorized users.

Yongming Luo ymluo@yic.ac.cn

1 College of Environmental Science and Engineering, Anhui Normal University, Wuhu 241002, China

2 Key Laboratory of Coastal Environmental Processes and Ecological Remediation, Yantai Institute of Coastal Zone Research, Chinese Academy of Sciences, Yantai 264003, China twentieth century. Most of these agents were subsequently buried underground or dumped at sea at several locations in China (Deng and Evans 1997), Europe (Daus et al. 2010), and Japan (Ishii et al. 2004). Numerous studies report the presence of these agents and their metabolites in soils at historical sites
3 Anhui Provincial Engineering Laboratory of Water and Soil Pollution Control and Remediation, Anhui Normal University, Wuhu 241002, China

4 Key Laboratory of Soil Environment and Pollution Remediation, Institute of Soil Science, Chinese Academy of Sciences, Nanjing 210008, China 
of warfare (D'Agostino and Provost 1992; Hanaoka et al. 2005). Clarks I and II have been found to be unstable in soils and can be simply metabolized to diphenylarsinic acid (DPAA) (Haas et al. 1998). Such DPAA contamination may represent a threat to human health due to its high mobility (Maejima et al. 2011a), bioavailability (Arao et al. 2009), cytotoxicity, and genotoxicity (Ochi et al. 2004). Effective strategies are therefore urgently required to control DPAA contamination in soils.

One effective solution to remove DPAA from contaminated soils is biostimulation using indigenous microorganisms that are stimulated by exogenous carbon sources and nutrients, and the main transformation pathway of DPAA involves dephenylation (Maejima et al. 2011b), methylation (Arao et al. 2009), and thionation (Nakamiya et al. 2013). Among these, thionation results in the most effective transformation of DPAA in biostimulated soils (Guan et al. 2012) and diphenylthioarsinic acid (DPTAA) was the major metabolite detected after incubation with sulfate and lactate (Hisatomi et al. 2013). Biostimulated sulfate reduction has already been tested as an effective strategy for the remediation of inorganic arsenic (As) in soils (Maguffin and Jin 2018) in which dissimilatory $\mathrm{Fe}(\mathrm{III})$ reduction driven by microbial metabolism of dissolved organic matter (DOM) is commonly implicated as a key factor affecting the mobility, and thereby the thionation, of inorganic As (Burton et al. 2008; Borch et al. 2009). However, our knowledge regarding the impact of Fe(III) reduction on the mobilization and thionation of DPAA in biostimulated soils is surprisingly limited.

Previous studies found that the amounts of DPAA sorbed onto the Acrisol and Andosol, which had more Fe/Al (hydr)oxides, were higher than those sorbed onto the Phaeozem and Fluvisol (Maejima et al. 2011a; Wang et al. 2013). A recent finding is that amorphous and crystalline $\mathrm{Fe}$ (hydr)oxides provide most sorption sites for DPAA in soils (Zhu et al. 2019). These results demonstrate that DPAA sorption onto soils are due mainly to ligand exchange reactions with hydroxyl groups on Fe (hydr)oxides. Limited studies have found that DPAA mobilization in a biostimulated Phaeozem was due primarily to the addition of sodium lactate at early stages but due to the near-complete Fe(III) reduction at later stages of incubation (Zhu et al. 2016a). Other studies propose that As mobilization is attributable mainly to $\mathrm{Fe}$ (III) reduction in carbon-limited environments (Masscheleyn et al. 1991; Nickson et al. 1998). However, Fe(III)-reducing microorganisms are capable of utilizing organic carbon compounds as electron donors (Kulkarni et al. 2018) and dissimilatory $\mathrm{Fe}$ (III) reduction was reported to proceed efficiently under carbon-rich conditions (Lovley and Phillips 1986a), which thereby enhance the effect of Fe(III) reduction on the mobilization of As (Eiche et al. 2017). In contract to the Phaeozem, DPAA mobilization from goethite was due mainly to Fe(III) reduction even in the presence of high concentrations of DOM
(Zhu et al. 2016a). Accordingly, we hypothesized that DOM in Fe-rich soils may enhance DPAA mobilization primarily by creating reducing conditions that promote $\mathrm{Fe}(\mathrm{III})$ reduction.

DPAA thionation in soils requires both sulfate and sufficient carbon sources, and the participation of sulfate-reducing bacteria (SRB) is expected (Guan et al. 2012). Studies have also investigated the process of SRB mediated thionation of DPAA (Guan et al. 2015) and phenylarsonic acid (PAA) (Hempel et al. 2009) in solution and have found that thioarsenate was formed chemically by a reaction of DPAA or PAA with sulfide. Combined results suggest that Fe(III) reduction may have a comparatively strong influence on the mobilization and thionation of DPAA in biostimulated soils. On the other hand, Fe(II) resulting from Fe(III) reduction can react with sulfide to form $\mathrm{FeS}$ or FeAsS-like precipitates (Bostick et al. 2004; Wilkin and Ford 2006) which can retard the formation of thioarsenate (Keimowitz et al. 2005; Sun et al. 2016). These findings highlight the potentially contrasting roles played by $\mathrm{Fe}(\mathrm{III})$ reduction in DPAA thionation. However, more experimental data are needed to rigorously address these issues.

Acrisols are a soil type with typically high Fe contents and they often occur in areas contaminated with chemical warfare agents (Deng and Evans 1997). Acrisols are also widely distributed in economically developed and grain-producing regions in south China and the risk of DPAA contamination in this soil type is therefore high. This provides potential conditions for sulfate-based biostimulation to remediate Fe-rich soils contaminated with DPAA. Consequently, our objective was to investigate the mobilization and thionation of DPAA in a biostimulated Acrisol and further to elucidate the impact of $\mathrm{Fe}$ (III) reduction on the thionation of DPAA. This may help to provide the scientific basis for clarifying the Fe (hydr)oxidemicrobe-DPAA interactions and developing remediation strategies for Acrisols contaminated with DPAA.

\section{Materials and methods}

\section{Reagents}

DPAA (97\%) standard was provided by Wako Pure Chemical Ind. Ltd. (Osaka, Japan). PAA was purchased from Aladdin Chemical Co. Ltd. (Shanghai, China). Methanol and formic acid used were of high-performance liquid chromatograph (HPLC) grade and were obtained from Merck KGaA (Darmstadt, Germany). Other reagents used were of analytical grade. All solutions were prepared with ultra-pure water (Milli-Q $18.2 \mathrm{M} \Omega \mathrm{cm}^{-1}$, Millipore, Burlington, MA). DPTAA was obtained by the chemical reaction of DPAA with hydrogen sulfide according to Stauder et al. (2005). 


\section{Soil}

A DPAA-free Orthic Acrisol (FAO-IUSS-ISRIC 2014) was collected from the surface horizon (top $15 \mathrm{~cm}$ ) of agricultural land at Yingtan, Jiangxi province, southeast China. The soil collected was air-dried and then sieved to obtain a particle size $\leq 2 \mathrm{~mm}$. Soil physicochemical properties were analyzed mainly according to the methods of $\mathrm{Lu}$ (2000). Soil $\mathrm{pH}$ was determined in supernatant of 1:2.5 soil-water mixture. Cation exchange capacity (CEC) and soil organic matter (SOM) were measured using sodium acetate-ammonium acetate extraction and dichromate oxidation, respectively. Fe was extracted using dithionite-citrate-sodium bicarbonate (DCB) and ammonium oxalate separately, representative of the free Fe forms (DCB- $\mathrm{Fe}_{2} \mathrm{O}_{3}$ ) consisting of crystalline and non-crystalline $\mathrm{Fe}$ oxides, and the active $\mathrm{Fe}$ forms (oxalate- $\mathrm{Fe}_{2} \mathrm{O}_{3}$ ) consisting of amorphous and poorly crystalline Fe oxides, respectively, and then measured using $o$-phenanthroline photometric method. Total As in soil was extracted by $\mathrm{HCl}-\mathrm{HNO}_{3}$ digestion, in the appropriate China national standard method GB/T 22105.2-2008 (General Administration of Quality Supervision, Inspection and Quarantine of the People's Republic of China 2008), and determined using atomic fluorescence spectrometry (AFS-930, Beijing Jitian Instrument Co., China). Soil particle composition was analyzed using a Mastersizer 2000F laser particle size analyzer (Malvern Instruments, UK). The main physico-chemical properties of the soil are as follows: $\mathrm{pH}, 4.94$; $\mathrm{CEC}, 13.70 \mathrm{cmol}_{\mathrm{c}} \mathrm{kg}^{-1}$; SOM, $1.23 \%$; DCB- $-\mathrm{Fe}_{2} \mathrm{O}_{3}, 37.3 \mathrm{~g} \mathrm{~kg}^{-1}$; oxalate- $\mathrm{Fe}_{2} \mathrm{O}_{3}$, $0.87 \mathrm{~g} \mathrm{~kg}^{-1}$; and total As, $16.1 \mathrm{mg} \mathrm{kg}^{-1}$. The mechanical composition of the soil is approximately $17.4 \%$ clay, $31.2 \%$ sand, and $51.4 \%$ silt.

\section{Soil incubation experiment}

The soil incubation experiment was prepared using 100-mL serum bottles as described by Zhu et al. (2016a). Soil cultures containing $20 \mathrm{~g}$ of the dried soil and $30 \mathrm{~mL}$ of the ultrapure water were prepared for anoxic and sulfide incubation. For sulfide cultures, sodium lactate (237 $\mu \mathrm{g} \mathrm{C} \mathrm{g}^{-1}$ dry soil) and sodium sulfate (426 $\mu \mathrm{g} \mathrm{S} \mathrm{g}^{-1}$ dry soil) were also added as carbon and sulfur sources, respectively. All bottles were sealed with butyl rubber and aluminum caps, then equipped with a catheter introduced into the water to simulate a natural anoxic or sulfatereducing environment. All cultures (eight replicates) were pre-incubated in the dark at $25{ }^{\circ} \mathrm{C}$ for 2 weeks in order to establish anoxic condition, then artificially spiked with DPAA at $30 \mathrm{mg} \mathrm{g}^{-1}$ dry soil with a sterile syringe and incubated for up to 8 weeks. All soil cultures were sealed during the incubation until destructive sampling took place after $0,2,4$, and 8 weeks of incubation.

\section{Sampling and analytical methods}

Four serum bottles were centrifuged at each sampling point, the supernatants were used for the analysis of dissolved DPAA, inorganic As, sulfate, sulfide, $\mathrm{Fe}(\mathrm{II}), \mathrm{Mn}(\mathrm{II})$, and total organic carbon (TOC), and the residues from the centrifuged supernatants were freeze-dried and used for the analysis of solid phase-associated DPAA, total sulfur, and carbon in the solid phase. The fractions of DPAA were determined using an HPLC-MS/MS method, with all samples diluted to give limited matrix effect (102-107\%) (Zhu et al. 2016b). Dissolved inorganic As was determined using AFS. Dissolved sulfate, sulfide, and $\mathrm{Fe}$ (II) were determined spectrophotometrically by barium sulfate turbidimetry (Lu 2000), copper sulfide turbidimetry (Cord-Ruwisch 1985), and ferrozine assay (Lovley and Phillips 1986b), respectively. Dissolved Mn(II) was analyzed by inductively coupled plasma optical emission spectrometry (ICP-OES, Optima 7000 DV, Perkin Elmer Co., Waltham, MA). TOC was measured using TOC-VCPH analyzer (Shimadzu, Japan). A part of the residue was extracted by $\mathrm{Na}_{2} \mathrm{HPO}_{4}$ and the resulting extract was subjected to HPLCMS/MS for the analysis of solid phase-associated DPAA (the detailed information was shown in the supplementary material), and another part of the residue was subjected to a CHNS elemental analyzer (Vario Micro cube, Elementar, Hanau, Germany) for the determination of total sulfur and carbon in the solid phase. The other four serum bottles were homogenized for the determination of $\mathrm{HCl}$-extractable $\mathrm{Fe}$ (II) and total $\mathrm{Fe}$ according to Kappler et al. (2004). Finally, supernatants and soil extracts (extracted with $\mathrm{Na}_{2} \mathrm{HPO}_{4}$, the detailed information was shown in the supplementary material) of slurries after 4 weeks of incubation were prepared for the analysis of As species. Eh and $\mathrm{pH}$ were determined using a Pt and glass electrode, respectively. The flowchart of the methodology is presented in Fig. 1. The details of the sampling and analytical methods were described in our previous study (Zhu et al. 2016a).

To prevent further oxidation during and after the sampling time, (1) all soil cultures were sampled under $\mathrm{N}_{2}$ atmosphere and $\mathrm{N}_{2}$ was introduced into all bottles containing supernatant or soil extract; (2) all supernatants were transferred to $4{ }^{\circ} \mathrm{C}$ freezer immediately after sampling; (3) the residues from the centrifuged supernatants were stored at $-20^{\circ} \mathrm{C}$ freezer immediately after sampling and then freeze-dried; (4) dissolved $\mathrm{Fe}(\mathrm{II}), \mathrm{Mn}(\mathrm{II})$, and sulfide were analyzed immediately after the sampling time; and (5) dissolved DPAA, inorganic As, As species, sulfate, and TOC were determined that day.

\section{Statistical analysis}

A two-way ANOVA was used to examine the effects of the incubation condition (anoxic, sulfide) and time on total DPAA 
Fig. 1 The flowchart of the methodology of the research

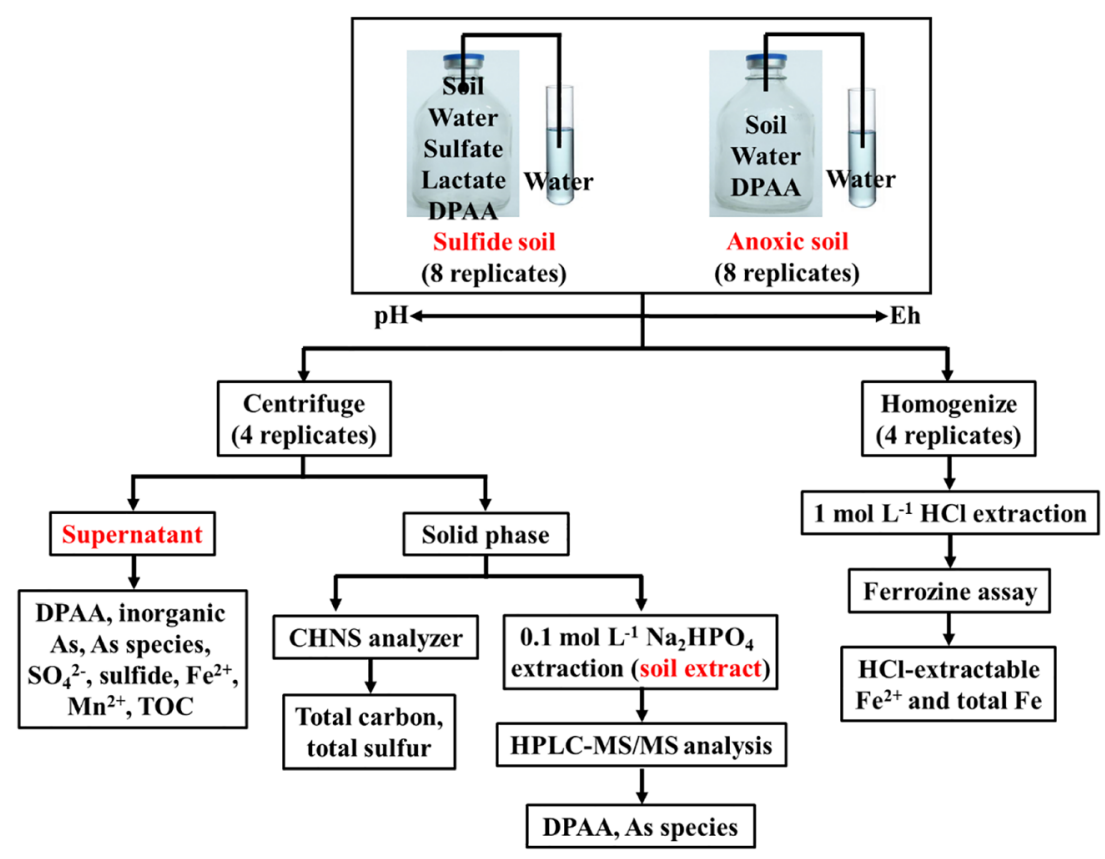

fractions. SPSS version 20.0 was used to perform the two-way ANOVA analysis.

\section{Results}

\section{Solid-solution partitioning of DPAA in anoxic and sulfide soil}

Changes in the fractions of dissolved and solid phaseassociated DPAA in anoxic and sulfide soil are presented in Fig. 2a, b, respectively. The fraction of dissolved DPAA in sulfide soil (41.8\%) was found to be much higher than that in anoxic soil (19.9\%) at time zero, due primarily to sodium lactate addition according to our sorption experiment (Fig. $\mathrm{S} 1)$. The fraction of dissolved DPAA then underwent a rapid increase within the initial 2 weeks and a steady decrease subsequently in both anoxic and sulfide soil (Fig. 2a, b). A more rapid increase in the fraction of dissolved DPAA was observed in sulfide soil, with a value close to $100 \%$ at 2 weeks, and DPAA was almost completely released into the solution subsequently (Fig. 2b). In contrast with sulfide soil, the fraction of dissolved DPAA in anoxic soil was lower compared with that of solid phase-associated DPAA throughout the incubation (Fig. 2a). These results indicate that DPAA was substantially mobilized in sulfide soil under our experimental conditions. Similarly, in a comparison of the concentration of dissolved inorganic As (Fig. 3) in anoxic and sulfide soil, a more pronounced mobilization of inorganic As was observed in sulfide soil.

\section{Transformation of DPAA in anoxic and sulfide soil}

Changes in the fractions of total DPAA in anoxic and sulfide soil during the incubation are shown in Fig. $2 \mathrm{a}, \mathrm{b}$, respectively. There was no decrease but rather a slight increase in the fraction of total DPAA in both anoxic and sulfide soil within the initial 2 weeks. A rapid and then slower decrease in total DPAA was observed in sulfide soil subsequently (Fig. 2b). Concurrently, total DPAA underwent a much slower decrease in anoxic soil compared with sulfide soil $(p<0.05)$ and the fractions of total DPAA finally decreased to 91.0 and $60.1 \%$ in anoxic and sulfide soil, respectively (Fig. 2a, b). Based on these results, a more rapid and final enhanced DPAA transformation was obtained in sulfide soil compared with anoxic soil. In addition, when compared with the changes in total DPAA over time after 2 weeks of incubation, similar trends were observed in the dissolved DPAA in both anoxic and sulfide soil (Fig. 2a, b), suggesting that DPAA was first released into the solution and then reacted or was degraded.

HPLC-MS/MS was further conducted to identify the metabolites of DPAA in the extracts and suspensions of anoxic and sulfide soil and the results are presented in Fig. 4. One novel peak at $t_{\mathrm{R}}=11.38-11.40 \mathrm{~min}$ occurred in the extracts of both anoxic and sulfide soil (Fig. $4 \mathrm{a}, \mathrm{c}$ ) corresponding to PAA according to the retention time and product ion (Table S1). Another (unknown) peak at $t_{\mathrm{R}}=22.56-22.60 \mathrm{~min}$ was observed in the suspensions of anoxic and sulfide soil as well as the extract of sulfide soil (Fig. 4b-d). Selected reaction monitoring (SRM) analysis of this peak showed a major 

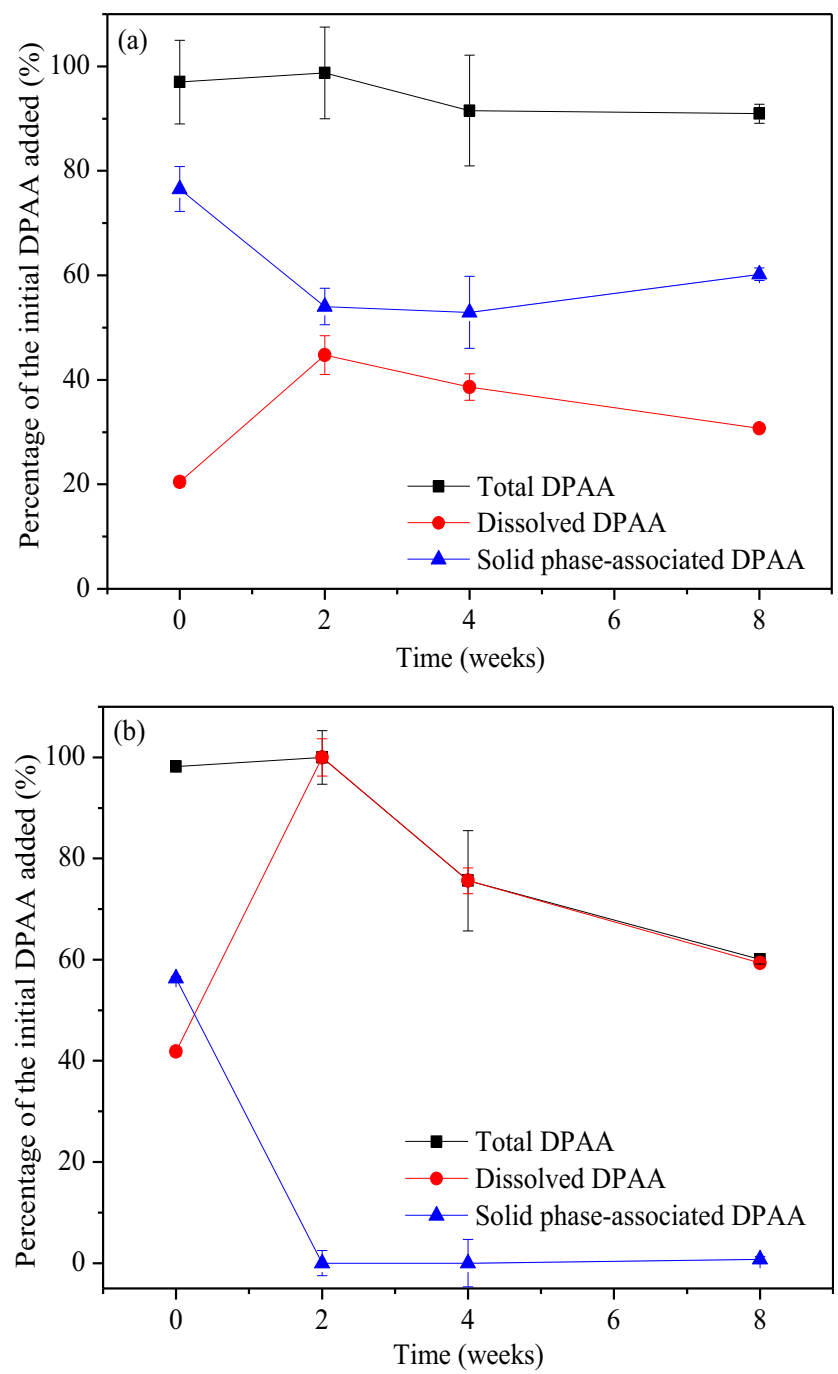

Fig. 2 Changes in the fractions of total, dissolved, and solid phaseassociated DPAA in anoxic (without addition of sulfate or lactate) (a) and sulfide (with the addition of sulfate and lactate) (b) soil. Each point and bar correspond to the mean $\pm \operatorname{SD}(n=4)$. The fractions of total DPAA were calculated as the ratio of the mass of total DPAA obtained at each sampling time to the mass of total DPAA added $(0.6 \mathrm{mg})$ at time zero. The fractions of dissolved and solid phase-associated DPAA were calculated as the ratio of the mass of dissolved and solid phase-associated DPAA obtained at each sampling time to the mass of total DPAA added $(0.6 \mathrm{mg})$ at time zero, respectively

molecular $[\mathrm{M}+\mathrm{H}]^{+}$ion peak at $\mathrm{m} / \mathrm{z}, 279.1$ and a fragment ion at $\mathrm{m} / \mathrm{z} 261.1$ (Table S1), demonstrating that DPTAA is another metabolite of DPAA. Based on the occurrence and peak areas of these two metabolites, it can be concluded that (1) mainly thionation and to a less extent dephenylation of DPAA were promoted in sulfide soil; (2) PAA formed was almost completely associated with the solid phase in both anoxic and sulfide soil (Fig. 4a, c); and (3) DPTAA existed mainly in dissolved form in anoxic soil while both dissolved (36.3\%) and solid phase-associated (63.7\%) forms occurred in sulfide soil (Fig. 4b-d).

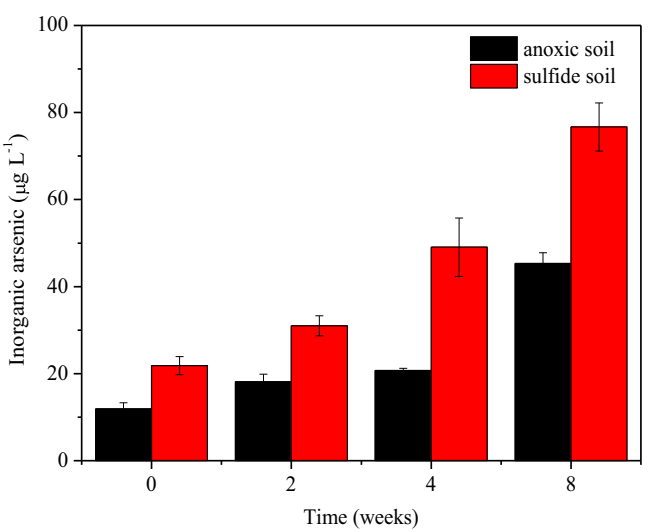

Fig. 3 Changes in the concentrations of dissolved inorganic arsenic in anoxic (without addition of sulfate or sodium lactate) and sulfide (with the addition of sulfate and sodium lactate) soil. All results were expressed as mean $\pm \mathrm{SD}(n=4)$

\section{Sulfate reduction in anoxic and sulfide soil}

Changes in the concentrations of dissolved sulfate and sulfide in anoxic and sulfide soil during the incubation are shown in Fig. 5a, b, respectively. Sulfate concentrations in sulfide soil decreased rapidly to $<10 \mathrm{mg} \mathrm{L}^{-1}$ at 4 -week incubation time (Fig. 5a) and sulfate reduction was concurrent with sulfide evolution (Fig. 5b). However, dissolved sulfide was at low levels $\left(<10 \mathrm{mg} \mathrm{L}^{-1}\right)$ throughout the incubation despite the significant depletion of dissolved sulfate. At the same time, the sulfide soil darkened quickly and the Eh values decreased to $<-100 \mathrm{mV}$ (Fig. S2) after 1 week of incubation. The ion products of $\mathrm{Fe}$ (II) (Fig. 6a) and sulfide were then calculated as $3.68 \times 10^{-8}, 1.97 \times 10^{-9}, 1.43 \times 10^{-8}$, and $1.06 \times 10^{-8}$ $(\mathrm{mol} \mathrm{L})^{-1}$ at $0,2,4$, and 8 weeks, respectively. All values exceeded the solubility product constant $\left(K_{\mathrm{sp}}\right)$ of FeS $(6.25 \times$ $10^{-18}$ ) and therefore indicate the occurrence of $\mathrm{FeS}$ precipitate which often forms under $\mathrm{Fe}$-rich sulfate-reducing conditions (Kocar et al. 2010; Flynn et al. 2014). A significant increase in the content of sulfur in the solid phase at the initial 4 weeks (Fig. S3) further demonstrates the formation of $\mathrm{FeS}$ and perhaps also other metal (e.g., Mn(II)) (Fig. S4) sulfide precipitates in sulfide soil. This may help to explain the surprisingly low concentrations of dissolved sulfide throughout the incubation (Luo et al. 2013). After 4 weeks of incubation, an increase in dissolved sulfate coupled with a decrease in solid phase-associated sulfur was observed in sulfide soil (Fig. 5a, Fig. S3). This indicates that sulfate sorbed on the solid phase is likely to be released into the solution at later incubation times.

In contrast with sulfide soil, no discernible depletion of sulfate but similar occurrence of dissolved sulfide was found in anoxic soil (Fig. 5a, b), suggesting that little sulfate reduction also occurred in anoxic soil under our experimental conditions. This result is consistent with the observation that DPAA was thionated to a less extent in anoxic soil than in sulfide soil (Figs. 2a, b and 4a-d). In addition, there was an 
Fig. 4 Extracted ion chromatograms (EIC)-HPLCMS/MS analysis of a extract and b suspension of anoxic soil (without addition of sulfate or sodium lactate), and $\mathbf{c}$ extract and d suspension of sulfide soil (with the addition of sulfate and sodium lactate) at 4-week incubation time: (1) PAA, (2) DPAA, and (3) DPTAA. The mass and structure used in selected reaction monitoring (SRM) for EIC-HPLC-MS/ MS analysis are presented in Table S1

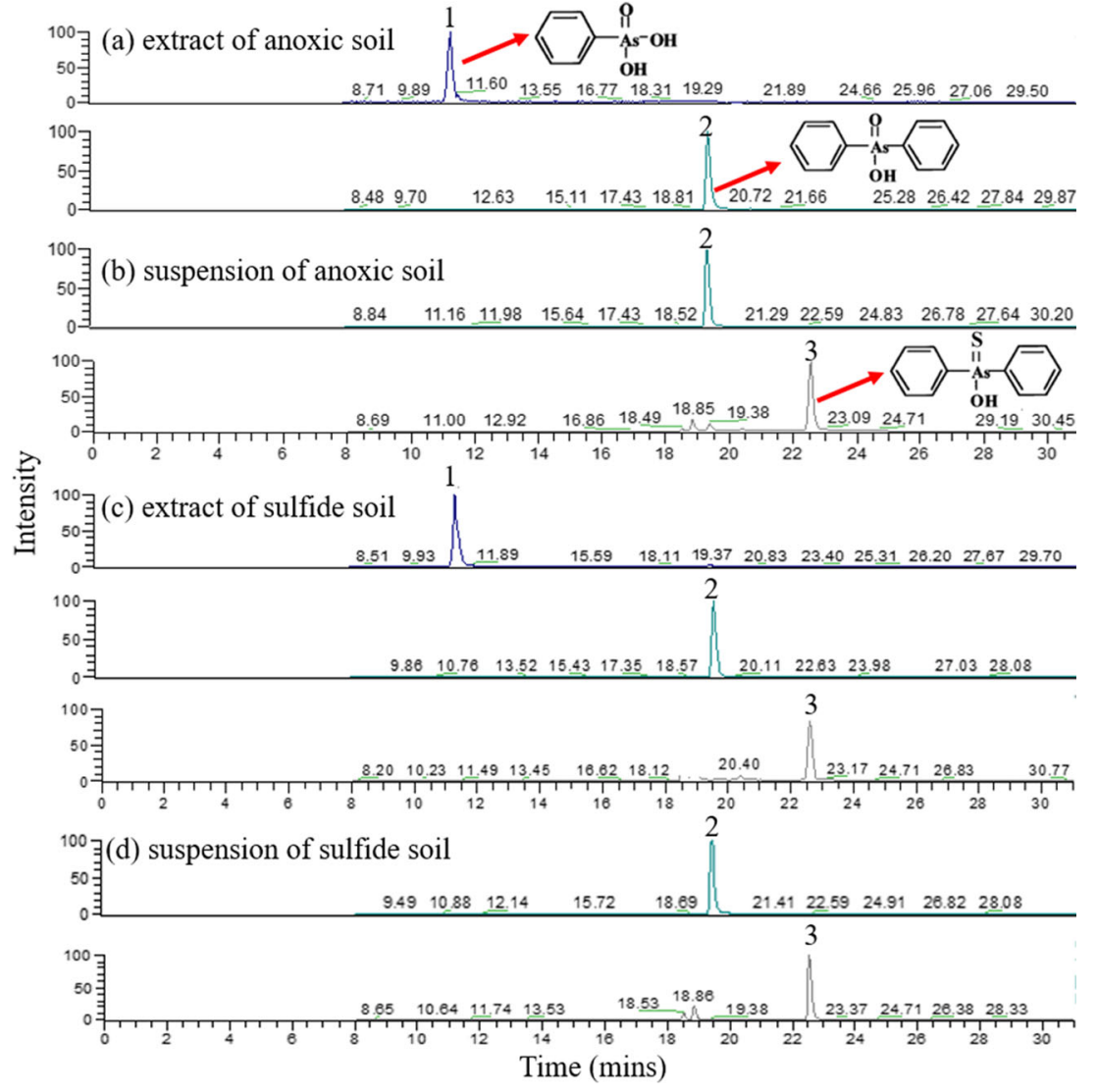

apparent release of sulfate during 4-8 weeks of incubation in anoxic soil (Fig. 5a), which may partly due to the increase of the $\mathrm{pH}$ (Kamprath et al. 1956), from 5.24 to 5.65 (Fig. S2), and partly due to the reductive dissolution of $\mathrm{Fe}$ (hydr)oxides (Fig. 6b) (Qu et al. 2003).

\section{$\mathrm{Fe}(\mathrm{III})$ reduction in anoxic and sulfide soil}

The occurrence of dissolved Fe(II) (Fig. 6a) and HClextractable $\mathrm{Fe}$ (II) (Fig. 6b) indicates the reductive dissolution of $\mathrm{Fe}(\mathrm{III})$ (hydr)oxides in sulfide soil. It can be seen that Fe(III) (hydr)oxides in sulfide soil underwent a rapid reductive dissolution throughout the incubation and $\sim 60 \%$ of $\mathrm{Fe}$ (III) (hydr)oxides were reduced at the end of the incubation (Fig. 6b). The concentration of dissolved TOC in sulfide soil decreased substantially during the incubation time (Fig. S5a), and thus, there is the potential for dissolved organic matter mineralization with $\mathrm{Fe}$ (III) as the ultimate electron acceptor (Lovley and Phillips 1986b). The resulting Fe(II) in sulfide soil was then sequestered in the solid phase while a little dissolved in the solution under sulfate-reducing conditions. This result corresponds well with the formation of FeS precipitate (Burton et al. 2014). In contrast to sulfide soil, no discernible reduction of $\mathrm{Fe}(\mathrm{III})$ (hydr)oxides was observed in anoxic soil (Fig. 6b). Additionally, the changes of both dissolved Fe(II) (Fig. 6a) and total carbon in the solid phase (Fig.
S5b) with incubation time showed transverse S-shaped profiles for sulfide soil, i.e., the curve displaying two peaks at 0 and 4-week incubation time, respectively, during which time $\mathrm{Fe}(\mathrm{III})$ reduction was followed by the formation of secondary Fe(II) minerals (Fig. 6a, b). This may be explained by the fact that Fe-bound organic carbon contributes substantially to total carbon in organic-rich soil (Zhao et al. 2016).

\section{Discussion}

\section{Impact of $\mathrm{Fe}$ (III) reduction on DPAA mobilization}

The enhanced DPAA mobilization in sulfide soil compared with anoxic soil at time zero (Fig. 2a, b) can be explained by the addition of sodium lactate (Fig. S1) and likely by their covering of sorption sites on Fe(III) (hydr)oxides (Polizzotto et al. 2006) or competitive sorption with DPAA (Redman et al. 2002). After this, DPAA was almost completely released into the solution in sulfide soil after 2 weeks of incubation and the fraction of dissolved DPAA was always higher than that in anoxic soil throughout the incubation (Fig. 2a, b). This is likely due to the rapid reductive dissolution of Fe(III) (hydr) oxides, which provide most sorption sites for DPAA in soils and therefore could represent the potentially mobilizable pool of DPAA under flooded conditions (Zhu et al. 2019), in 

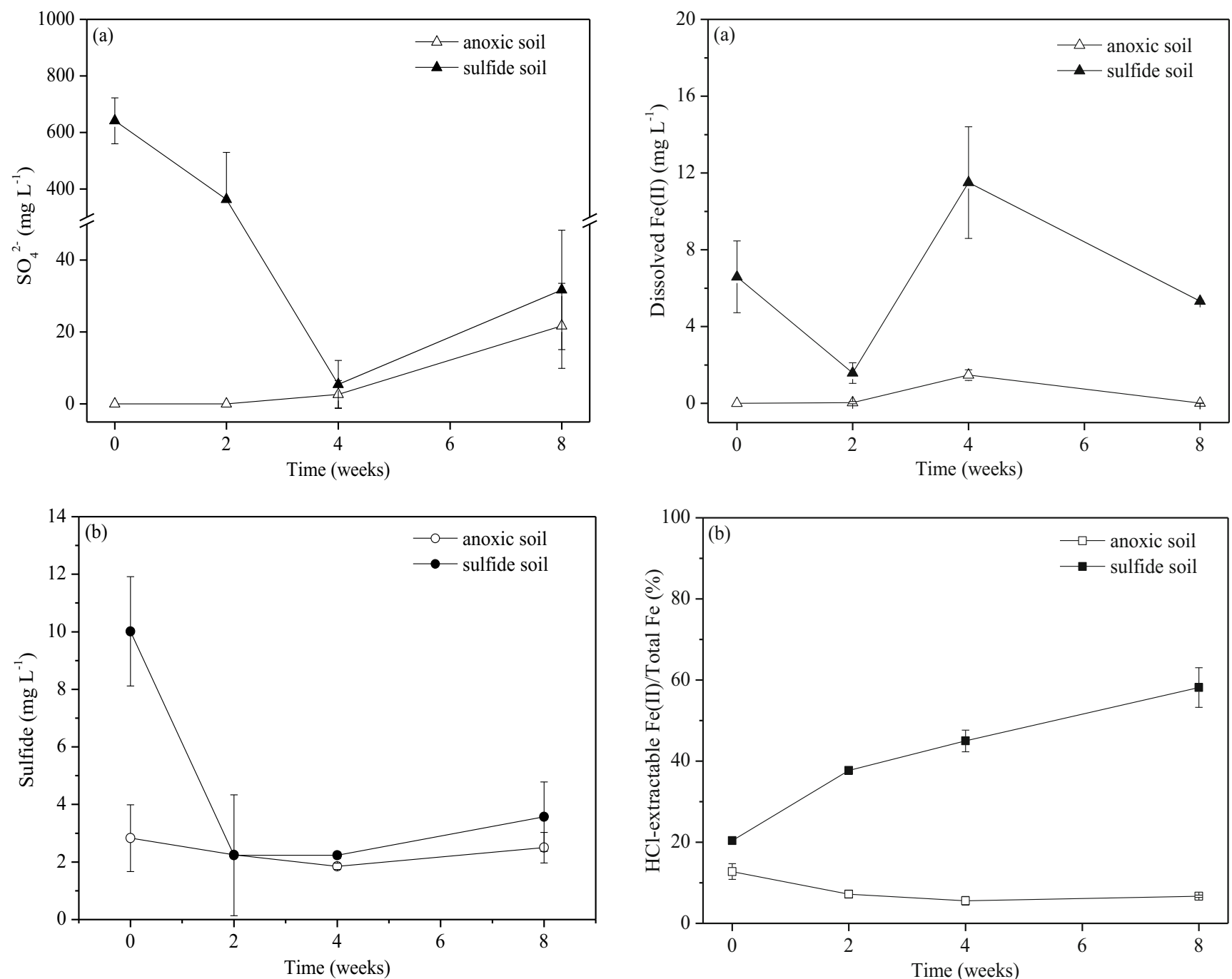

Fig. 5 Changes in the concentrations of dissolved sulfate (a) and sulfide (b) in anoxic (without addition of sulfate or sodium lactate) and sulfide (with the addition of sulfate and sodium lactate) soil. Each point and bar correspond to the mean $\pm \mathrm{SD}(n=4)$

sulfide soil (Fig. 6a, b). It should be noted that Fe(III) reduction proceeded throughout the incubation and $<60 \%$ of the $\mathrm{Fe}(\mathrm{III})$ (hydr)oxides was reduced at the end of the incubation (Fig. 6b). Theoretically, this is not enough for the complete release of DPAA in sulfide soil. Possible explanations may include the following: (1) amorphous and poorly crystalline (i.e., oxalate extractable) Fe (hydr)oxides are usually more susceptible to reductive dissolution compared with well-crystallized ones (Weber et al. 2010), and the former have been demonstrated to be the main component responsible for DPAA sorption in Acrisols (Zhu 2017); (2) coverage of sorption sites on the surface of residual Fe(III) (hydr)oxides by sodium lactate or its competitive sorption; (3) competitive sorption of PAA and DPTAA due to their occurrence in the solid phase (Fig. 4c, d); and (4) competitive sorption of inorganic As in solution (Fig. 3).

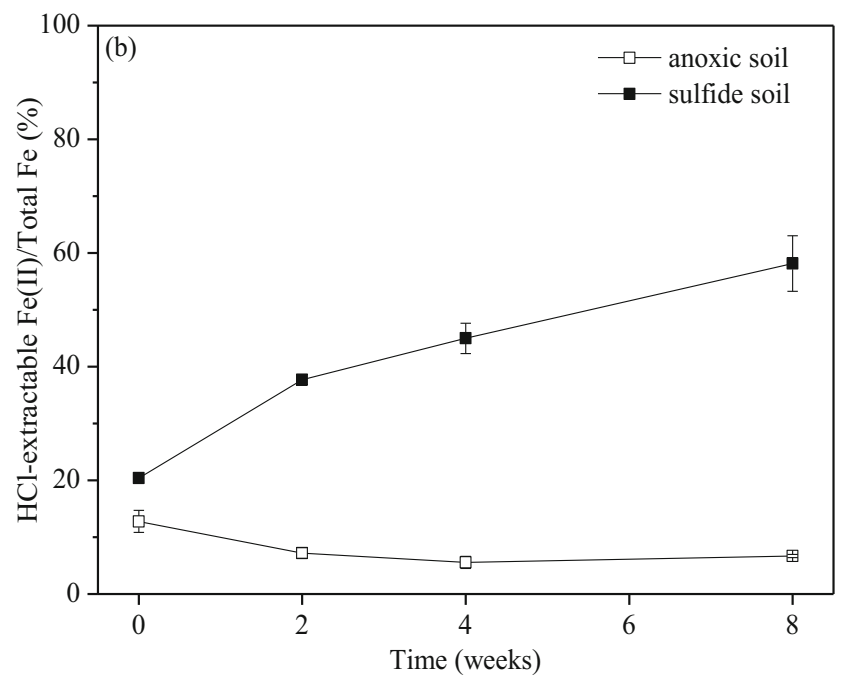

Fig. 6 Changes in the concentrations of dissolved Fe(II) (a) and fractions of $\mathrm{HCl}$-extractable $\mathrm{Fe}(\mathrm{II})$ to $\mathrm{HCl}$-extractable total $\mathrm{Fe}$ (b) in anoxic (without addition of sulfate or sodium lactate) and sulfide (with the addition of sulfate and sodium lactate) soil. Each point and bar correspond to the mean $\pm \mathrm{SD}(n=4)$

A significant increase in the concentration of dissolved inorganic As during the incubation was observed in sulfide soil (Fig. 3), and we suggest this resulted from the desorption of solid phase-associated inorganic As, rather than a complete mineralization of DPAA due to the following reasons. Firstly, there is no direct evidence that DPAA or PAA can be completely mineralized in flooded or sulfate-reducing soils according to the reported literature (Arao et al. 2009; Maejima et al. 2011b; Hisatomi et al. 2013; Guan et al. 2015). Secondly, the reductive dissolution of Fe(III) (hydr)oxides in sulfide soil, as indicated by the increased concentrations of dissolved $\mathrm{Fe}(\mathrm{II})$ and $\mathrm{HCl}$-extractable $\mathrm{Fe}(\mathrm{II})$ (Fig. 6a, b), has been widely demonstrated as a predominant mechanism causing inorganic As mobilization (Van Geen et al. 2006; Yamaguchi et al. 2011). Thirdly, there was also a significant increase over time in the concentration of dissolved 
Fig. 7 Schematic diagram for the impacts of $\mathrm{Fe}$ (III) and sulfate reduction on the mobilization and transformation of DPAA in Acrisol with the addition of sulfate and sodium lactate

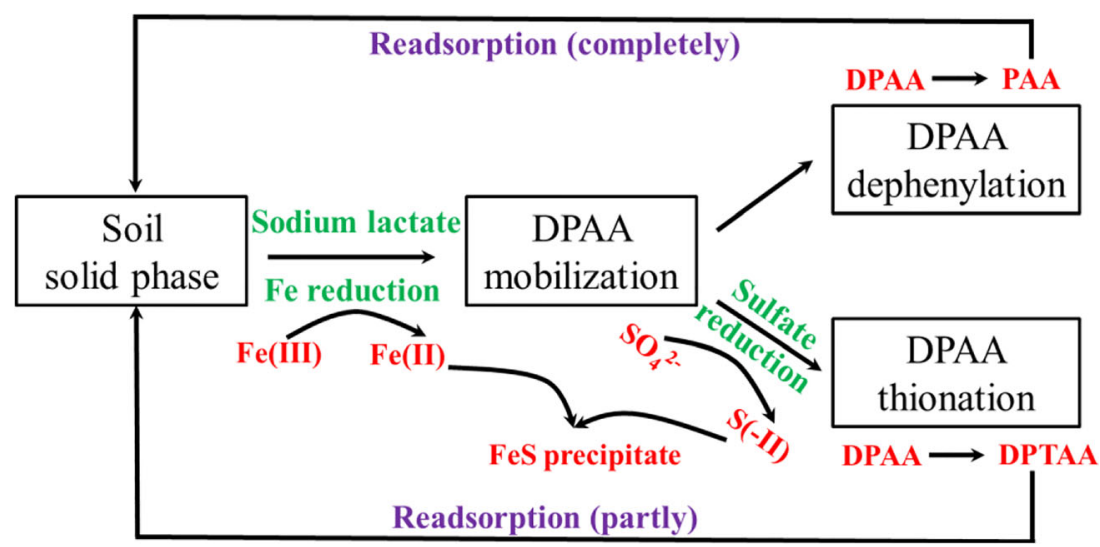

inorganic As in anoxic soil (Fig. 3), in which the decrease of total DPAA fraction occurred to only a small degree (Fig. 2a); the only mechanism which seems able to account for the mobilization of inorganic As in both anoxic and sulfide soil is biological reduction of As(V) (Weber et al. 2010), but more experimental data are required to give a definitive answer. In addition, in contrast to $\mathrm{Fe}(\mathrm{III})$ reduction, the subsequent formed FeS may sequestrate inorganic As via sorption or coprecipitation (Wilkin and Ford 2006). A substantial mobilization of inorganic As in sulfide soil (Fig. 3) therefore indicates that the partitioning of inorganic As mainly depends on $\mathrm{Fe}$ (III) reduction and to less extent on secondary FeS. This finding corresponds well with the fact that FeS sorbs much less inorganic As than Fe (hydr)oxides (Xu et al. 2011; Burton et al. 2013), and the lack of incorporation of inorganic As into secondary FeS may result in the mobilization of inorganic As (O'Day et al. 2004).

Our previous study has shown that a large proportion of DPAA $(74.5 \%)$ in a biostimulated Phaeozem was mobilized by sodium lactate addition at early stages and a small proportion of DPAA was further mobilized due to the near-complete reduction of Fe (hydr)oxides at later incubation stages (Zhu et al. 2016a). When comparing our results for the Acrisol with those previously reported for the Phaeozem, it seems that sodium lactate has a limited effect on promoting DPAA mobilization in the Acrisol (Fig. 2a, b). This may be explained by the higher amount of crystalline and non-crystalline (i.e., DCB extractable) Fe (hydr)oxides in the Acrisol and therefore a stronger sorption capacity toward DPAA (Wang et al. 2013). Moreover, the ratio of $\mathrm{HCl}$-extractable $\mathrm{Fe}(\mathrm{II})$ to $\mathrm{HCl}$ extractable total Fe reached nearly $40 \%$ in the Acrisol (Fig. 6b) but $90 \%$ in the Phaeozem (Zhu et al. 2016a), when DPAA was almost completely released into the solution. This difference may result from the smaller fraction of oxalateextractable $\mathrm{Fe}$ (hydr)oxides and therefore the less active, reduction-susceptible Fe forms in the Acrisol (2.33\%) compared to the Phaeozem $(9.65 \%)$. This finding provides evidence for the importance of Fe speciation rather than total
Fe content only when considering the impact of $\mathrm{Fe}$ (III) reduction on DPAA mobilization in soils.

\section{Impact of Fe and sulfate reduction on DPAA thionation}

There was a rapid and final enhanced transformation of DPAA in sulfide soil compared with anoxic soil (Fig. 2a, b), and both DPTAA and PAA were identified as the major metabolites of DPAA in sulfide soil (Fig. 4c, d). This could be attributed to microbial dephenylation and sulfate reduction as first reported by Maejima et al. (2011b) and Guan et al. (2012). Previous studies have also found that DPTAA and PAA were the major metabolites of DPAA in soil under sulfate-reducing (Hisatomi et al. 2013) and flooded (Maejima et al. 2011b) conditions, respectively. The discrepancy between our results and those previously reported may be due to their different $\mathrm{C} / \mathrm{S}$ ratios. It seems that DPAA thionation is favored at relatively low $\mathrm{C} / \mathrm{S}$ ratios where $\mathrm{SRB}$ have some advantage in competing with other anaerobic microorganisms (O'Flaherty et al. 1999) that might be involved in DPAA dephenylation. However, more experimental data are required to confirm the impact of $\mathrm{C} / \mathrm{S}$ ratio on DPAA dephenylation and thionation.

Despite the coexistence of DPTAA and PAA in sulfide soil, a more significant promotion of DPAA thionation than dephenylation was observed in sulfide soil compared with anoxic soil (Fig. 4a-d), suggesting that exogenous sulfate reduction contributes greatly to DPAA thionation. However, DPTAA was also found in anoxic soil without the addition of sulfate (Fig. 4b), suggesting that DPAA can also be thionated but to a less extent when subjected to slight endogenous sulfate reduction.

Our results show that DPAA was first released into the solution and then thionated in both anoxic and sulfide soil (Fig. 2a, b) and we therefore propose that Fe(III) reduction may contribute substantially to DPAA mobilization and thereby its subsequent thionation in sulfide soil (Fig. 7). Moreover, DPTAA has been previously found to be obtained in solution by a reaction of DPAA and sulfide, but without SRB (Stauder 
et al. 2005). For these reasons, it can be concluded that enhanced DPAA mobilization resulted from Fe(III) reduction coupled with substantial sulfate reduction which both contribute to the more pronounced DPAA thionation in sulfide soil. Nevertheless, the fraction of total DPAA in sulfide soil still remained high $(60.1 \%)$ even after 8 weeks of incubation (Fig. $2 b)$. A more complete thionation of DPAA was observed in our previous study carried out in a Phaeozem, where only $3.4 \%$ of the total DPAA remained unreacted after 8 weeks of incubation (Zhu et al. 2016a). The difference between soil types may be due to the relatively high content of DCBextractable $\mathrm{Fe}$ in the Acrisol (37.3 $\mathrm{g} \mathrm{kg}^{-1}$ ) compared with the Phaeozem $\left(11.5 \mathrm{~g} \mathrm{~kg}^{-1}\right)$ and therefore a greater formation of FeS precipitate in the Acrisol becomes possible. However, precipitation of $\mathrm{FeS}$ may remove sulfide from solution, an unfavorable condition for the thionation of As (O'Day et al. 2004). These results suggest that Fe(III) reduction may have played a double role in the DPAA thionation process, i.e., on the one hand promoting the mobilization and thereby the further thionation of DPAA and on the other hand reducing DPAA thionation by reacting with sulfide and forming FeS precipitate (Fig. 7).

\section{Conclusions}

Substantial mobilization and thionation of DPAA were observed in a biostimulated Acrisol with the addition of sulfate and sodium lactate. The increased DPAA mobilization was due to sodium lactate addition and $\mathrm{Fe}(\mathrm{III})$ reduction at the initial and subsequent times, respectively, and the fraction of oxalate extractable $\mathrm{Fe}$ seems to contribute more to the effect of $\mathrm{Fe}(\mathrm{III})$ reduction on DPAA mobilization. Furthermore, Fe(III) reduction may have played contrasting roles in the DPAA thionation process, i.e., promoting the mobilization and thereby the further thionation of DPAA and reducing DPAA thionation by consuming sulfide and forming FeS precipitate. The results highlight the contrasting roles of $\mathrm{Fe}(\mathrm{III})$ reduction in DPAA thionation in a biostimulated Acrisol and the need to consider both Fe speciation and total Fe content when evaluating the impact of $\mathrm{Fe}(\mathrm{III})$ reduction on the mobilization and thionation of DPAA in contaminated soils.

Funding information We are grateful for the funding from the National Natural Science Foundation of China (nos. 41807117 and 41230858), the Key Project of Natural Science Research of Universities in Anhui Province (no. KJ2018A0315), the Doctoral Research Start-up Funds Project of Anhui Normal University (no. 2018XJJ50), the Cultivation Project on Excellent Undergraduates' Thesis (design, create) of Anhui Normal University (no. pyjh2018487), and the Project of Innovation and Entrepreneurship Training for College Students (no. 201910370072).

\section{References}

Arao T, Maejima Y, Baba K (2009) Uptake of aromatic arsenicals from soil contaminated with diphenylarsinic acid by rice. Environ Sci Technol 43(4):1097-1101

Borch T, Kretzschmar R, Kappler A, Cappellen PV, Ginder-Vogel M, Voegelin A, Campbell K (2009) Biogeochemical redox processes and their impact on contaminant dynamics. Environ Sci Technol 44(1):15-23

Bostick BC, Chen C, Fendorf S (2004) Arsenite retention mechanisms within estuarine sediments of Pescadero, CA. Environ Sci Technol 38:3299-3304

Burton ED, Bush RT, Sullivan LA, Johnston SG, Hocking RK (2008) Mobility of arsenic and selected metals during re-flooding of ironand organic-rich acid-sulfate soil. Chem Geol 253:64-73

Burton ED, Johnston SG, Planer-Friedrich B (2013) Coupling of arsenic mobility to sulfur transformations during microbial sulfate reduction in the presence and absence of humic acid. Chem Geol 343:12-24

Burton ED, Johnston SG, Kocar BD (2014) Arsenic mobility during flooding of contaminated soil: the effect of microbial sulfate reduction. Environ Sci Technol 48(23):13660-13667

Cord-Ruwisch R (1985) A quick method for the determination of dissolved and precipitated sulfides in cultures of sulfate-reducing bacteria. J Microbiol Methods 4:33-36

D'Agostino PA, Provost LR (1992) Determination of chemical warfare agents, their hydrolysis products and related compounds in soil. J Chromatogr A 589(1-2):287-294

Daus B, Hempel M, Wennrich R, Weiss H (2010) Concentrations and speciation of arsenic in groundwater polluted by warfare agents. Environ Pollut 158(11):3439-3444

Deng HM, Evans POM (1997) Social and environmental aspects of abandoned chemical weapons in China. Nonprol Rev 4(3):101-108

Eiche E, Berg M, Hönig SM, Neumann T, Lan VM, Pham TKT, Pham HV (2017) Origin and availability of organic matter leading to arsenic mobilisation in aquifers of the Red River Delta, Vietnam. Appl Geochem 77:184-193

FAO-IUSS-ISRIC (2014) World reference base for soil resources. World soil resources report 106

Flynn TM, O’Loughlin EJ, Mishra B, DiChristina TJ, Kemner KM (2014) Sulfur-mediated electron shuttling during bacterial iron reduction. Science 344(6187):1039-1042

General Administration of Quality Supervision, Inspection and Quarantine of the People's Republic of China (2008) Soil qualityanalysis of total mercury, arsenic and lead contents-atomic fluorescence spectrometry - part 2: analysis of total arsenic contents in soils (GB/T 22105.2-2008). China Standard Press, Beijing (in Chinese)

Guan L, Hisatomi S, Fujii K, Nonaka M, Harada N (2012) Enhanced transformation of diphenylarsinic acid in soil under sulfatereducing conditions. J Hazard Mater 241:355-362

Guan L, Shiiya A, Hisatomi S, Fujii K, Nonaka M, Harada N (2015) Sulfate-reducing bacteria mediate thionation of diphenylarsinic acid under anaerobic conditions. Biodegradation 26(1):29-38

Haas R, Schmidt TC, Steinbach K, von Löw E (1998) Chromatographic determination of phenylarsenic compounds. Fresenius J Anal Chem 361(3):313-318

Hanaoka S, Nagasawa E, Nomura K, Yamazawa M, Ishizaki M (2005) Determination of diphenylarsenic compounds related to abandoned chemical warfare agents in environmental samples. Appl Organomet Chem 19:265-275

Hempel M, Daus B, Vogt C, Weiss H (2009) Natural attenuation potential of phenylarsenicals in anoxic groundwaters. Environ Sci Technol 43:6989-6995

Hisatomi S, Guan L, Nakajima M, Fujii K, Nonaka M, Harada N (2013) Formation of diphenylthioarsinic acid from diphenylarsinic acid 
under anaerobic sulfate-reducing soil conditions. J Hazard Mater 262:25-30

Ishii K, Tamaoka A, Otsuka F, Iwasaki N, Shin K, Matsui A, Endo G, Kumagai Y, Ishii T, Shoji S, Ogata T, Ishizaki M, Doi M, Shimojo N (2004) Diphenylarsinic acid poisoning from chemical weapons in Kamisu, Japan. Ann Neurol 56(5):741-745

Kamprath EJ, Nelson WL, Fitts JW (1956) The effect of pH, sulfate and phosphate concentrations on the adsorption of sulfate by soils 1 . Soil Sci Soc Am J 20(4):463-466

Kappler A, Benz M, Schink B, Brune A (2004) Electron shuttling via humic acids in microbial iron (III) reduction in a freshwater sediment. FEMS Microbiol Ecol 47:85-92

Keimowitz AR, Zheng Y, Chillrud SN, Mailloux B, Jung HB, Stute M, Simpson HJ (2005) Arsenic redistribution between sediments and water near a highly contaminated source. Environ Sci Technol 39(22):8606-8613

Kocar BD, Borch T, Fendorf S (2010) Arsenic repartitioning during biogenic sulfidization and transformation of ferrihydrite. Geochim Cosmochim Ac 74(3):980-994

Kulkarni HV, Mladenov N, McKnight DM, Zheng Y, Kirk MF, Nemergut DR (2018) Dissolved fulvic acids from a high arsenic aquifer shuttle electrons to enhance microbial iron reduction. Sci Total Environ 615:1390-1395

Lovley DR, Phillips EJP (1986a) Availability of ferric iron for microbial reduction in bottom sediments of the freshwater tidal Potomac River. Appl Environ Microbiol 52(4):751-757

Lovley DR, Phillips EJP (1986b) Organic matter mineralization with reduction of ferric iron in anaerobic sediments. Appl Environ Microbiol 51(4):683-689

Lu RK (2000) Methods of soil and agrochemical analysis. China Agricultural Science and Technology Press, Beijing (In Chinese)

Luo T, Tian HX, Guo Z, Zhuang GQ, Jing CY (2013) Fate of arsenate adsorbed on nano- $\mathrm{TiO}_{2}$ in the presence of sulfate reducing bacteria. Environ Sci Technol 47(19):10939-10946

Maejima Y, Murano H, Iwafune T, Arao T, Baba K (2011a) Adsorption and mobility of aromatic arsenicals in Japanese agricultural soils. Soil Sci Plant Nutr 57(3):429-435

Maejima Y, Arao T, Baba K (2011b) Transformation of diphenylarsinic acid in agricultural soils. J Environ Qual 40(1):76-82

Maguffin SC, Jin QS (2018) Testing biostimulated sulfate reduction as a strategy of arsenic remediation in iron-rich aquifers. Chem Geol 493:80-86

Masscheleyn PH, Delaune RD, Patrick WH Jr (1991) Effect of redox potential and $\mathrm{pH}$ on arsenic speciation and solubility in a contaminated soil. Environ Sci Technol 25:1414-1419

Nakamiya K, Yoshikane M, Tomoko H, Shibata Y (2013) Transformation of diphenylarsinic acid and related compounds in groundwater: production of thiol-containing arsenicals. Environ Chem 10(1):17-21

Nickson R, McArthur J, Burgess W, Ahmed KM, Ravenscroft P, Rahmanñ M (1998) Arsenic poisoning of Bangladesh groundwater. Nature 395(6700):338

Ochi T, Suzuki T, Isono H, Kaise T (2004) In vitro cytotoxic and genotoxic effects of diphenylarsinic acid, a degradation product of chemical warfare agents. Toxicol Appl Pharmacol 200(1):64-72

O'Day PA, Vlassopoulos D, Root R, Rivera N (2004) The influence of sulfur and iron on dissolved arsenic concentrations in the shallow subsurface under changing redox conditions. P Natl Acad Sci USA 101(38): 13703-13708

O'Flaherty V, Colohan S, Mulkerrins D, Colleran E (1999) Effect of sulphate addition on volatile fatty acid and ethanol degradation in an anaerobic hybrid reactor. II: microbial interactions and toxic effects. Bioresour Technol 68(2):109-120

Polizzotto ML, Harvey CF, Li GC, Badruzzman B, Ali A, Newville M, Sutton S, Fendorf S (2006) Solid-phases and desorption processes of arsenic within Bangladesh sediments. Chem Geol 228:97-111

Qu D, Zhang YP, Schnell S, Conrad R (2003) Reduction of iron oxides and its effect on microbial processes in anaerobic paddy soil. Acta Pedol Sin 40(6):858-863 (in Chinese)

Redman AD, Macalady DL, Ahmann D (2002) Natural organic matter affects arsenic speciation and sorption onto hematite. Environ Sci Technol 36(13):2889-2896

Stauder S, Raue B, Sacher F (2005) Thioarsenates in sulfidic waters. Environ Sci Technol 39:5933-5939

Sun J, Quicksall AN, Chillrud SN, Mailloux BJ, Bostick BC (2016) Arsenic mobilization from sediments in microcosms under sulfate reduction. Chemosphere 153:254-261

Van Geen A, Zheng Y, Cheng Z, Aziz Z, Horneman A, Dhar RK, Maolloux B, Stute M, Weinman B, Goodbred S, Seddique AA, Hoque MA, Ahmed KM (2006) A transect of groundwater and sediment properties in Araihazar, Bangladesh: further evidence of decoupling between As and Fe mobilization. Chem Geol 228:85-96

Wang AN, Li SY, Teng Y, Liu WX, Wu LH, Zhang HB, Huang YJ, Luo YM, Christie P (2013) Adsorption and desorption characteristics of diphenylarsenicals in two contrasting soils. J Environ Sci 25:11721179

Weber FA, Hofacker AF, Voegelin A, Kretzschmar R (2010) Temperature dependence and coupling of iron and arsenic reduction and release during flooding of a contaminated soil. Environ Sci Technol 44: $116-122$

Wilkin RT, Ford RG (2006) Arsenic solid-phase partitioning in reducing sediments of a contaminated wetland. Chem Geol 228:156-174

Xu LY, Zhao ZX, Wang SF, Pan RR, Jia YF (2011) Transformation of arsenic in offshore sediment under the impact of anaerobic microbial activities. Water Res 45:6781-6788

Yamaguchi N, Nakamura T, Dong D, Takahashi Y, Amachi S, Makino T (2011) Arsenic release from flooded paddy soils is influenced by speciation, Eh, pH, and iron dissolution. Chemosphere 83:925-932

Zhao Q, Poulson SR, Obrist D, Sumaila S, Dynes JJ, McBeth JM, Yang Y (2016) Iron-bound organic carbon in forest soils: quantification and characterization. Biogeosciences 13:4777-4788

Zhu M (2017) Binding mechanism and biological/chemical remediation of diphenylarsinic acid in the soils. Dissertation, Yantai Institute of Coastal Zone Research, Chinese Academy of Sciences (in Chinese)

Zhu M, Tu C, Hu XF, Zhang HB, Zhang LJ, Wei J, Li Y, Luo YM, Christie P (2016a) Solid-solution partitioning and thionation of diphenylarsinic acid in a flooded soil under the impact of sulfate and iron reduction. Sci Total Environ 569-570:1579-1586

Zhu M, Tu C, Zhang HB, Luo YM, Christie P (2016b) Simultaneous determination of diphenylarsinic and phenylarsinic acids in amended soils by optimized solvent extraction coupled to HPLCMS/MS. Geoderma 270:109-116

Zhu M, Hu XF, Tu C, Luo YM, Yang RY, Zhou SB, Cheng NN, Rylott EL (2019) Speciation and sorption structure of diphenylarsinic acid in soil clay mineral fractions using sequential extraction and EXAFS spectroscopy. J Soil Sediment 20:763-774

Publisher's note Springer Nature remains neutral with regard to jurisdictional claims in published maps and institutional affiliations. 